\title{
Influence of Upper Frequency Boundary on Consonant Perception in Normal Hearing and Cochlear Implant Adults
}

\author{
Son-A Chang ${ }^{1}$, Min-Hyun Park², Seung-Ha Oh³, Kyung-Min Lee ${ }^{4}$ \\ 'Department of Speech Language Therapy \& Aural Rehabilitation, College of Health \& Welfare, Woosong University, Daejeon, Korea \\ ${ }^{2}$ Department of Otolaryngology-Head and Neck Surgery, Boramae Medical Center, Seoul Metropolitan Government-Seoul National University, \\ Seoul, Korea \\ ${ }^{3}$ Departments of Otolaryngology-Head and Neck Surgery, ${ }^{4}$ Neurology, College of Medicine, Seoul National University, Seoul, Korea
}

\begin{abstract}
Purpose: Although some studies argue that it is worthy for cochlear implant $(\mathrm{Cl})$ users to have frequency information above 3,000 $\mathrm{Hz}$ for consonant recognition, it is not clear whether $\mathrm{Cl}$ patients make use of this information, especially in Korean. In this experiment, we tested whether consonant recognition in $\mathrm{Cl}$ patients depended on the utilization of information from 3,000 to 8,000 Hz. Methods: We conducted consonant recognition tests in Korean [3 syllable structures: vowel-consonant-vowel (VCV), consonant-vowel (CV), and vowelconsonant (VC)] pronounced by one male and one female speakers for 3 normal hearing $(\mathrm{NH})$ and $3 \mathrm{Cl}$ adults with 9 low-pass filtering frequency conditions. Results: Both groups showed decreased correction scores as cut-off frequency getting lower. $\mathrm{Cl}$ subjects scored twice errors to $\mathrm{NH}$ subjects across frequency conditions. The cut-off frequency of 1,500 Hz brought a significant decrease of consonant recognition. Consonants in VCV syllable recognized better than VC and CV syllable in both groups. Fricatives and affricates in the manner of articulation and alveolar and palatal in the place of articulation are the ones that benefit from high frequency coding. Alveolar plosive sounds were most difficult sounds in both groups and this confirms previous studies of consonant recognition in Korean. Conclusion: $\mathrm{NH}$ and $\mathrm{Cl}$ groups demonstrated poorer consonant recognition as cut-off frequency decreased with relatively large decrements of $\mathrm{Cl}$ group. The information above $3,000 \mathrm{~Hz}$ conveys little information for consonant recognition in the normal and $\mathrm{Cl}$ subjects while some $\mathrm{Cl}$ subjects utilized information up to $6,000 \mathrm{~Hz}$. There were large individual differences, particularly in $\mathrm{Cl}$ group.
\end{abstract}

Key Words: Frequency information, Consonant perception, Cochlear implant.

Received: June 23, 2017 / Revised: June 30, 2017 / Accepted: June 30, 2017

Correspondence: Son-A Chang, Department of Speech Language Therapy and Aural Rehabilitation, 171 Dongdaejeon-ro, Dong-gu, Daejeon 34606, Korea Tel: +82-42-630-9221 / Fax: +82-42-630-9229 / E-mail: parfum0@hanmail.net

\section{INTRODUCTION}

In speech, consonants have less energy and lie in relatively higher frequency band than vowels. Consonants were more difficult to identify than vowels, irrespective of age or ear, and accuracy in identification (Goodglass, 1973). Besides, loss of audibility of consonants adversely affects speech perception more than that of vowels (Schow \& Nerbonne, 2002). Shannon (2002) reviewed speech perception research over 25 years and concluded that quantity and quality of spectral information seemed to be most critical for speech understanding compare to temporal and amplitude cues. Especially patients with sensory neural hearing loss suffered by deteriorated speech recognition ability due to loss of high frequency audibility. Speech recognition predicted by Speech
Intelligibility Index (SII) indicated deterioration by high frequency components. However, it has been revealed that relatively less impact of high frequency amplification on recognition scores in hearing impaired people (Ching et al., 1998; Hogan \& Turner, 1998; Murray \& Byrne, 1986; Rankovic, 1991; Turner \& Brus, 2001). These phenomena were obvious with severe hearing loss patients (Hogan \& Turner, 1998; Turner \& Cummings, 1999). Started from Vickers et al. (2001), it has been widely accepted that cochlear dead region can cause these phenomena.

In consonants, manner and place of articulation and voicing are important factors for discriminating speech signals. It has been proved that the place of articulation is more difficult than the manner of articulation (Kim et al., 2014; Milchard \& Cullington, 2004; Pisoni \& Remez, 2005; Turner \& Brus, 2001; Tyler \& 
Moore, 1992; Välimaa et al., 2002). But, voicing, which is one of the main discriminating features of speech sounds, has not as much impact on speech recognition as place and manner. In Korean language, voicing is even not the discrimination features. The place of articulation and phonation types are also the most difficult features in perception of consonants in Korean language (Kim et al., 2014; Lee \& Lee, 2000). With these evidences, we can speculate that frequency bands and features of speech affect speech perception, especially consonant discrimination.

Park \& Lee (2001) investigated changes in speech intelligibility with frequency cutting with normal hearing $(\mathrm{NH})$ and highfrequency hearing loss patients in Korean language. Information above $3-4 \mathrm{kHz}$ had least impact on speech recognition with $40-$ $50 \mathrm{~dB}$ HL input sounds, which is considered important to identification of many speech sounds in English (French \& Steinberg, 1947). In Korean, there is no consonant cluster, which means that it could be assumed Korean consonants can have more vowel transition information. On the other hand, it has been proved that vowel-consonant (VC) is more difficult condition for identifying and producing consonants than consonantvowel (CV) (Abraham, 1989; Hochmann et al., 2011; Owens et al., 1972). On the contrast, Lee \& Lee (2000) showed children with hearing impairment recognized consonants in VC better than that in CV. They explained that this is because there are only seven post-vocalic consonants belonging to stops, nasals, and liquid sounds which are relatively easy to hear. Kim et al. (2014) also demonstrated that final consonants were to be discriminated better in frequency limiting conditions in normal listeners.

Since Miller \& Nicely (1955) proposed that the number of errors in perceptual confusion patterns represented differences in speech perception mechanism, many researchers investigated which features of speech affect more than others on speech recognition using the confusion type speech recognition test. The confusion type consonant recognition tests can examine every phoneme in target language regardless of the occurring frequency of the phonemes or linguistic difficulty. In Park \& Lee (2001)'s study, they used monosyllable identification test for measuring speech recognition scores. They discussed that the speech materials which contain uneven distribution of phonemes could affect the results of the study. Besides, formant transition between consonant and vowel can affect perception of consonants so that to compare perception among consonants it is needed to use same vowel context. Kim et al. (2014) investigated how normal people perceive Korean consonants using confusion test. However, there has been not many studies conducted to examine how well all the consonants are recognized comparing normal and cochlear im- plant (CI) users.

CI has been verified as highly valid and reliable device for hearing restoration of severe to profound hearing loss. CI devices provide much clearer speech intelligibility than hearing aids and much more high frequency audibility that assumes to help speech perception. However, researches demonstrated that CI subjects were not able to fully utilize the spectral information provided by the number of electrodes used in their implants (Friesen et al., 2001). The listeners with CI could tolerate a large section of missing spectral information in the middle and basal regions, as long as the rest of the spectrum was intact, on the other hand, speech recognition is severely reduced if the missing spectral information is in the critical low-frequency region (Shannon et al., 2002).

This device is used worldwide, and assumed that it is providing sufficient speech information in all used languages. Frequency allocation of CI has an English basis. Korean might have different major frequency bands from other languages, which is lower than other languages such as English, French, or Russian (De Boysson-Bardies et al., 1989; Kim \& Lee, 2001) although several studies argued that no differences were found in long term frequency spectrum across languages (Byrne et al., 1994). Furthermore, in terms of Korean speech, it might have more emphasis on mid and low frequency for discriminating speech (Noh \& Lee, 2012) and have different frequency function from English (Lee \& Kim, 2012). To investigate on this, comparison on consonant recognition between best $\mathrm{CI}$ performers and $\mathrm{NH}$ adults was performed using the confusion type of consonant recognition test. We recorded consonant recognition test materials and then gradually cut frequency bands using default frequency allocation setting in Nucleus $24 \mathrm{CI}$ system. In normal subjects, we can observe how frequency bands affect on consonant recognition and compare the recognition difference between $\mathrm{NH}$ and CI users. So this investigation intended to demonstrate that 1 ) the change in consonant recognition abilities of $\mathrm{NH}$ and $\mathrm{CI}$ subjects with band pass filtering according to the frequency table of Nucleus CI system, 2) the comparison of performance in syllable structures and manner and place of articulation, and 3) analysis on consonant recognition errors of the subjects to examine the recognition characteristics of each subject.

\section{MATERIALS AND METHODS}

\section{Subjects}

The subjects included three $\mathrm{NH}$ adults and three $\mathrm{CI}$ users who were all females. In the $\mathrm{NH}$ group, their average age was 33 years 
(34, 38, and 27 years respectively) and in the CI group, their average age was 28 years $(28,29$, and 27 years respectively). The selection criterion of $\mathrm{NH}$ subjects was pure tone audiometry (PTA) threshold less than $20 \mathrm{~dB} \mathrm{HL}(250 \mathrm{~Hz}$ to $6,000 \mathrm{~Hz}$ ) and average PTA was $8 \mathrm{~dB} \mathrm{HL}(5,14$, and $5 \mathrm{~dB}$ respectively). The selection criteria of CI subjects were 1) post-lingual deafness, 2) less than $40 \mathrm{~dB}$ HL CI thresholds, 3) more than 1-year CI experience, and 4) more than $85 \%$ of open-set sentence test. The average unaided PTA was 91.7 dB HL and average CI threshold was $34.2 \mathrm{~dB}$ HL in the CI group. All the CI subjects wore Esprit3G of Cochlear Ltd. using Advanced Combination Encoder strategy and Only the third subject (CI 3) in the CI group was using contralateral hearing aid. This study was confirmed by Seoul National University Institutional Review Board (IRB number 0805-079-245) and all the subjects were agreed to the condition of the study voluntarily. Information about the CI subjects was provided in the Table 1.

\section{Consonant recognition test and frequency modulation}

Speech materials included 18 items of VCV test, 18 items of CV test, and 7 items of VC test. They were one- and two-syllable nonsense syllables composed of VCV, CV, and VC combination with vowel /a/ (Figure 1, 2).

Those were recorded in double-walled sound-proof room by one male and one female talker who used standard Korean language. The speech signal was digitized at a sampling rate 48 $\mathrm{kHz}$ with 16-bit resolution. The cutoff frequencies were set according to the default frequency bands setting for Esprit3G. It consisted of nine frequency bands which increase at an exponential rate. And its upper frequency limits were 760, 1,414, $1,080,1,866,2,463,3,347,4,595,6,308$, and $8,658 \mathrm{~Hz}$. So the experimental band-pass frequency bands were $120-8,658,120-$ $6,308,120-4,595,120-3,347,120-2,463,120-1,866,120-1,414$, $120-1,080$, and $120-760 \mathrm{~Hz}$.

Using Fast Fourier Transform (FFT) algorithm, the original signals which were recorded as wave files were transformed to frequency based data. In These data, outsides of the target frequency band were 0 processed with a computer program using $\mathrm{C}$ lan- guage, which was developed for this study. A rectangular filter was used for the cutting, which has aliasing distortion at the edge of the signal, but preserves more intensity information than the filters with sloping. The data were inversed to the wave files using Inversed FFT (IFFT) algorithm. These manipulated speech stimuli were randomized in terms of stimuli matrix and frequency. Two sets of the stimuli by the two speakers were used for six subjects. Total 774 number of response were obtained by each subject.

\section{Test procedures}

Speech stimuli were transmitted via computer compact disk player in an isolated quiet room. For the $\mathrm{NH}$ subjects they were to listen to the stimulus lists in the preferred ear mono-aurally through earphone. They were told to speak out the syllables they heard as they touched the target syllables on the stimulus cards. CI subjects were provided the speech stimuli in the implanted ear through input adaptor and cable that were hooked directly into the speech processors. CI subjects used their final map which has been used more than 6 months and has all 20 electrodes on.

To make results constant, the sound level of stimuli was maximal on the volume setting in the computer and $50 \%$ of maximal output on the audio-wave program. The loudness level was reported to be comfortable by the subjects.

\begin{tabular}{|c|c|c|c|c|}
\hline aga (아가) & ana (아나) & ada (아다) & aca (아라) & ama (아마) \\
\hline aba (아바) & asa (아사) & $\mathrm{ak}^{* a}$ (아까) & atca (아자) & atc $^{\mathrm{h} a}$ (아차) \\
\hline $\mathrm{ak}^{\mathrm{h}} \mathrm{a}$ (아카) & at $^{\mathrm{h}} \mathrm{a}$ (아타) & $\mathrm{ap}^{\mathrm{h} a}$ (아파) & aha (아하) & $\mathrm{at}^{*} \mathrm{a}$ (아따) \\
\hline $\mathrm{ap}^{*} \mathrm{a}$ (아빠) & $\mathrm{as}^{*} \mathrm{a}$ (아싸) & $\mathrm{atc}^{*} \mathrm{a}$ (아짜) & & \\
\hline
\end{tabular}

Figure 1. VCV stimuli list of consonant recognition test. VCV: vowel-consonant-vowel.

\begin{tabular}{|c|c|c|c|c|}
\hline $\mathrm{ka}$ (가) & $\mathrm{na}$ (나) & $\mathrm{ta}$ (다) & la (라) & $\mathrm{ma}$ (마) \\
\hline $\mathrm{pa}$ (바) & $\mathrm{sa}$ (사) & an $\urcorner$ (앙) & tca (자) & $\mathrm{tc}^{\mathrm{h}} \mathrm{a}$ (차) \\
\hline $\mathrm{k}^{\mathrm{ha}}$ (카) & $\mathrm{t}^{\mathrm{h}} \mathrm{a}$ (타) & $\mathrm{p}^{\mathrm{h}} \mathrm{a}$ (파) & ha (하) & $\mathrm{ak}\urcorner$ (악) \\
\hline at $\urcorner$ (앋) & al (알) & $\mathrm{am}\urcorner$ (암) & $\mathrm{ap}\urcorner$ (압) & $\operatorname{an}\urcorner$ (안) \\
\hline $\mathrm{k}^{*} \mathrm{a}$ (까) & $\mathrm{t}^{*} \mathrm{a}$ (따) & p*a (빠) & $\mathrm{s}^{*} \mathrm{a}$ (싸) & $\mathrm{tc}^{*} \mathrm{a}$ (짜) \\
\hline
\end{tabular}

Figure 2. $\mathrm{CV}+\mathrm{VC}$ stimuli list of consonant recognition test. $\mathrm{CV}$ : consonant-vowel, $\mathrm{VC}$ : vowel-consonant.

Table 1. Demographic information of $\mathrm{Cl}$ subjects

\begin{tabular}{lccc}
\hline \multicolumn{1}{c}{ Categories } & CI \#1 & CI \#2 & CI \#3 \\
\hline Age/sex & $28 / \mathrm{F}$ & $29 / \mathrm{F}$ & $27 / \mathrm{F}$ \\
Hearing threshold in better ear & $100 \mathrm{~dB} \mathrm{HL}$ & $100 \mathrm{~dB} \mathrm{HL}$ & $75 \mathrm{~dB} \mathrm{HL}$ \\
CI threshold & $30 \mathrm{~dB} \mathrm{HL}$ & $35-40 \mathrm{~dB} \mathrm{HL}$ & $30-40 \mathrm{~dB} \mathrm{HL}$ \\
HA use on opposite ear & - & - & + \\
Duration of deafness & 15 yrs & $10 \mathrm{mon}$ & 20 yrs +1 mon \\
Causes of deafness & Progressive & Sudden & Progressive + sudden \\
\hline
\end{tabular}

CI: cochlear implant, HA: hearing aid 


\section{Data analysis}

The error analysis was performed to compare NH and CI subjects. It was analyzed by error number frequency and percentage. Mann-Whitney test and two-way ANOVA and post-hoc analysis were used. In addition to this, error matrix was analyzed.

\section{RESULTS}

This study meant to analyze and compare Korean consonant recognition errors between $\mathrm{NH}$ and $\mathrm{CI}$ adults according to the amount of frequency information in speech. The analysis was performed in two folds which were a hearing factor and a speech acoustical factor. The Hearing factor was analyzed by total consonant recognition errors and errors according to the frequency bands and the speech acoustic factor was analyzed by syllable structures and phoneme error analysis.

\section{Comparison of total error between $\mathrm{NH}$ and $\mathrm{Cl}$}

Out of the total 774 mean chance, the error percentages were $19.4 \%$ in $\mathrm{NH}$ group and $43.5 \%$ in CI group. There was a significant difference between $\mathrm{NH}$ and $\mathrm{CI}$ groups $(\mathrm{z}=-3.712, p<0.001)$ (Figure 3). CI group (mean $=336.96, \mathrm{SD}=22.304)$ made errors about twice than normal group $($ mean $=150.3, \mathrm{SD}=18.512)$.

$\mathrm{NH}$ subjects made no errors in VCV condition when they had all the frequency information from $120-8,658 \mathrm{~Hz}$. However, VC and $\mathrm{CV}$ errors occurred in these frequency bands. $\mathrm{NH}$ subjects demonstrated less than $15 \%$ of error percentage in each frequency band and syllable structure down to $1,866 \mathrm{~Hz}$ for VCV test, 2,463 $\mathrm{Hz}$ for $\mathrm{CV}$ test and for VC test, which were one or two raw error scores (Table 2). Meanwhile CI group showed more than 15\% of error numbers from the beginning and the errors were continuously increased along with frequency reduction. Errors of CI subjects were more increased due to subject \#3 (Figure 4). She showed marked error numbers from the beginning of frequency reduc- tion. She was the only bimodal user and this result revealed that she relied less on CI device than the other two subjects.

\section{Frequency bands and syllable structures}

Figure 3 showed that consonant recognition errors were increased along with the frequency reduction in all the subjects. In $\mathrm{NH}$ group, nine frequency bands brought a significant difference $(\mathrm{F}=37.843, p<0.001)$. Post-hoc analysis revealed that frequency bands down from $1,414 \mathrm{~Hz}$ made significant differences with upper frequency bands. And the errors increased significantly in $1,414,1,080$, and $760 \mathrm{~Hz}$ of the upper frequency limits. It is similar in CI group that the frequency bands made a significant difference in consonant recognition errors ( $\mathrm{F}=5.775, p=0.001)$, but only $1,080 \mathrm{~Hz}$ and $760 \mathrm{~Hz}$ bands made significant differences. This is because the errors started to occur with all the frequency information. Figure 4 showed how CI subject \#3 affected the error rate in CI group.

With the syllable structures, there were significant differences between subject groups (VCV: $\mathrm{F}=4.116, p=0.003, \mathrm{CV}: \mathrm{F}=4.396$, $p=0.002$, VC: $\mathrm{F}=7.374, p<0.001)$. VCV structure was the easiest condition in three conditions as predicted (NH: 16.0\%, CI:

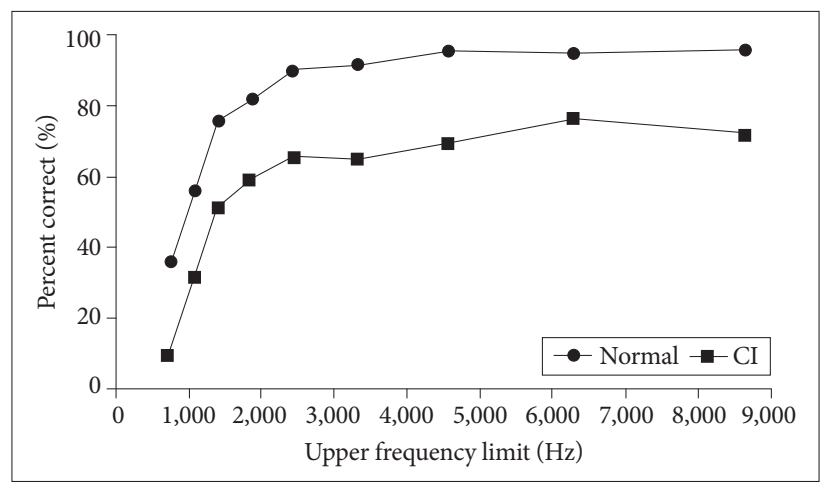

Figure 3. Consonant recognition errors across average conditions by band-pass frequency cutting of $\mathrm{NH}$ and $\mathrm{Cl}$ subjects $(n=6$, lower frequency limit $=120 \mathrm{~Hz}$ ). $\mathrm{NH}$ : normal hearing, $\mathrm{Cl}$ : cochlear implant.

Table 2. Recognition errors by syllable structures and talker's gender in $\mathrm{NH}$ and $\mathrm{Cl}$ subjects (\%)

\begin{tabular}{lrrrrrr}
\hline Subjects & No. of error & VCV condition & CV condition & VC condition & Male voice & Female voice \\
\hline S1 & $116(14.8)$ & $34(10.5)$ & $62(19.1)$ & $20(15.9)$ & $61(15.8)$ & $55(14.2)$ \\
S2 & $142(18.3)$ & $49(15.1)$ & $69(21.3)$ & $24(19.0)$ & $60(15.6)$ & $82(21.2)$ \\
S30 & $194(25.1)$ & $72(22.2)$ & $85(26.2)$ & $37(29.4)$ & $89(23.0)$ & $105(27.1)$ \\
Mean & $150.3(19.4)$ & $51.7(16.0)$ & $72.0(22.2)$ & $27.0(21.4)$ & $70.0(18.1)$ & $80.7(20.9)$ \\
CI1 & $281(36.3)$ & $89(27.5)$ & $146(45.1)$ & $46(36.5)$ & $140(36.2)$ & $141(36.4)$ \\
CI2 & $256(33.1)$ & $84(25.9)$ & $130(40.1)$ & $42(33.3)$ & $123(31.8)$ & $133(34.4)$ \\
Mean CI1 \& & $268.5(34.7)$ & $86.5(26.7)$ & $138(42.6)$ & $44(19.2)$ & $131.5(34.0)$ & $137(35.4)$ \\
CI3 & $474(61.2)$ & $176(54.3)$ & $215(66.4)$ & $82(65.1)$ & $244(63.0)$ & $229(59.2)$ \\
Mean & $337.0(43.5)$ & $116.3(35.9)$ & $163.7(50.5)$ & $56.7(45.0)$ & $169.0(43.7)$ & $167.7(43.3)$ \\
\hline
\end{tabular}

NH: normal hearing, CI: cochlear implant, VCV: vowel-consonant-vowel, CV: consonant-vowel, VC: vowel-consonant 
35.9\%). Interestingly, even VC condition (NH: $21.4 \%$, CI: 45.0\%) showed less error numbers than CV (NH: 22.2\%, CI: 50.5\%) in both subject groups, errors in VC started from higher frequency band than the CV condition. The error percentage gap between VCV and CV was greater in CI group (Table 2). Only \#3 in CI groups made significantly more errors than normal subjects in the VCV and CV condition and she showed significantly more errors than other five subjects in the VC condition (Figure 5).

\section{Error analysis}

CI subjects demonstrated more diffused error patterns than $\mathrm{NH}$ subjects as predicted. The most frequent errors were found in consonant $/ \mathrm{t}^{\mathrm{h}} /$ within $\mathrm{VCV}$ and $\mathrm{CV}$ conditions and $\left./ \mathrm{k}\right\urcorner /$ within VC condition in both subject groups. In contrast, the least frequent errors were different between $\mathrm{CI}$ and $\mathrm{NH}$ groups, which were $/ \mathrm{t} 6 /$ in $\mathrm{VCV}, / \mathrm{m} /$ in $\mathrm{CV}$, and $/ \mathrm{h}\urcorner /$ in $\mathrm{VC}$ in $\mathrm{NH}$ group and $/ \mathrm{t}_{6} /$ in $\mathrm{VCV}, / \mathrm{k} / \mathrm{h}$ in $\mathrm{CV}$, and $\left./ \mathrm{p}\right\urcorner /$ in $\mathrm{VC}$ in $\mathrm{CI}$ group. As expected, aspirated alveolar sound was the most difficult

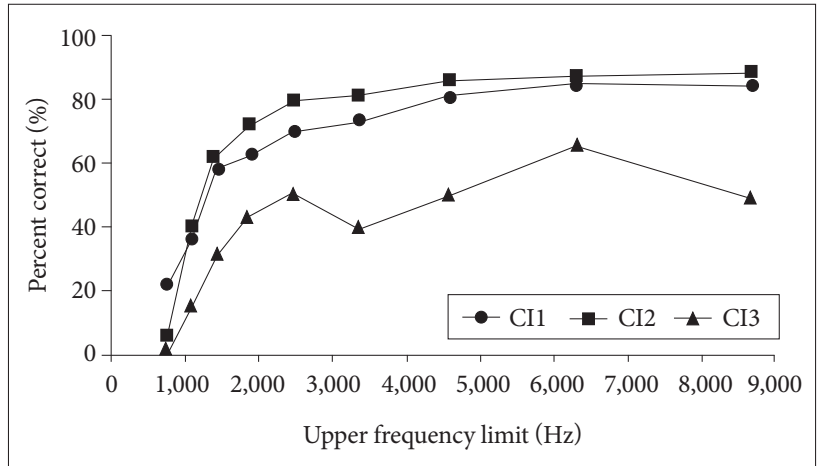

Figure 4. Consonant recognition errors across average conditions by band-pass frequency cutting of individual $\mathrm{Cl}$ subjects $(n=3$, lower frequency limit $=120 \mathrm{~Hz}$ ). $\mathrm{Cl}$ : cochlear implant. phoneme whereas nasal and liquid sounds were easier than the other phonemes in both subject groups which place relatively low frequency range. However, $\mathrm{NH}$ and $\mathrm{CI}$ subjects recognized lax affricate /tc/ sound easily and CI subjects recognized aspirated velar sound as the easiest in CV condition, which were not expected.

In error analysis, we left out CI \#3 because she made a lot more errors than the other two subjects and confused error patterns. The normal group and CI \#1 and \#2 showed about the same substitution patterns that were much more recognition errors in the place of articulation than the manner of articulation (Figure 6, 7). In the CV condition, the errors in the manner of articulation increased in CI \#1 and \#2, but still the place of articulation was more difficult. $\mathrm{NH}$ group showed no manner of articulation substitution in the VC condition, meanwhile, CI \#1 and \#2 still showed the manner of articulation substitution.

\section{DISSCISIONS}

As expected, CI group made twice more errors than $\mathrm{NH}$ group across frequency bands. This may due to the fact that the CI group showed more initial errors and continuously increased error numbers than the $\mathrm{NH}$ group. Comparing to $8,658 \mathrm{~Hz}$, consonant recognition errors were markedly increased from $1,414 \mathrm{~Hz}$ in the $\mathrm{NH}$ group and $1,080 \mathrm{~Hz}$ in the CI group. High frequency information upper from $2,000 \mathrm{~Hz}$ might be redundant for Korean consonant recognition in normal people. However, it was still important to the hearing impaired people with cochlear implants. It seems that the higher frequency information can help some CI recipients to recognize speech.

Errors in recognition occurred from full frequency informa-
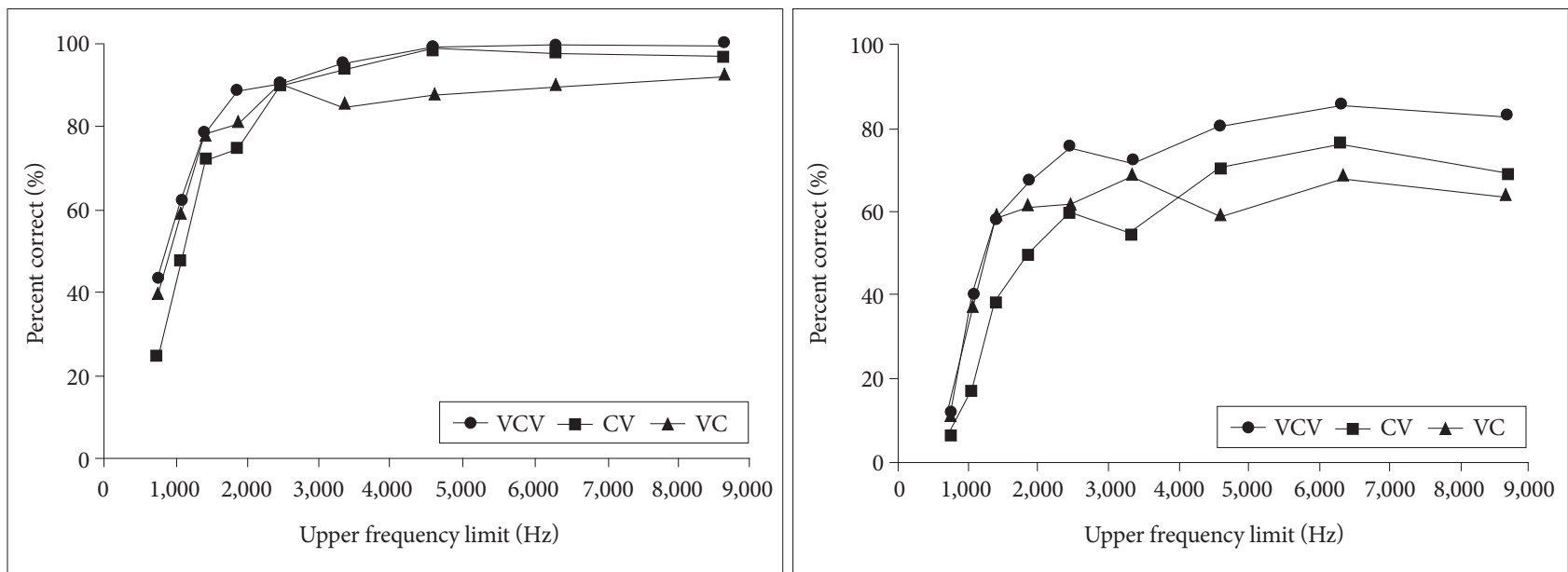

Figure 5. Consonant recognition errors by band-pass frequency cutting and syllable structures of $\mathrm{NH}$ and $\mathrm{Cl}$ subjects $(n=6)$, lower frequency limit $=120 \mathrm{~Hz}$. NH: normal hearing, $\mathrm{Cl}$ : cochlear implant. 

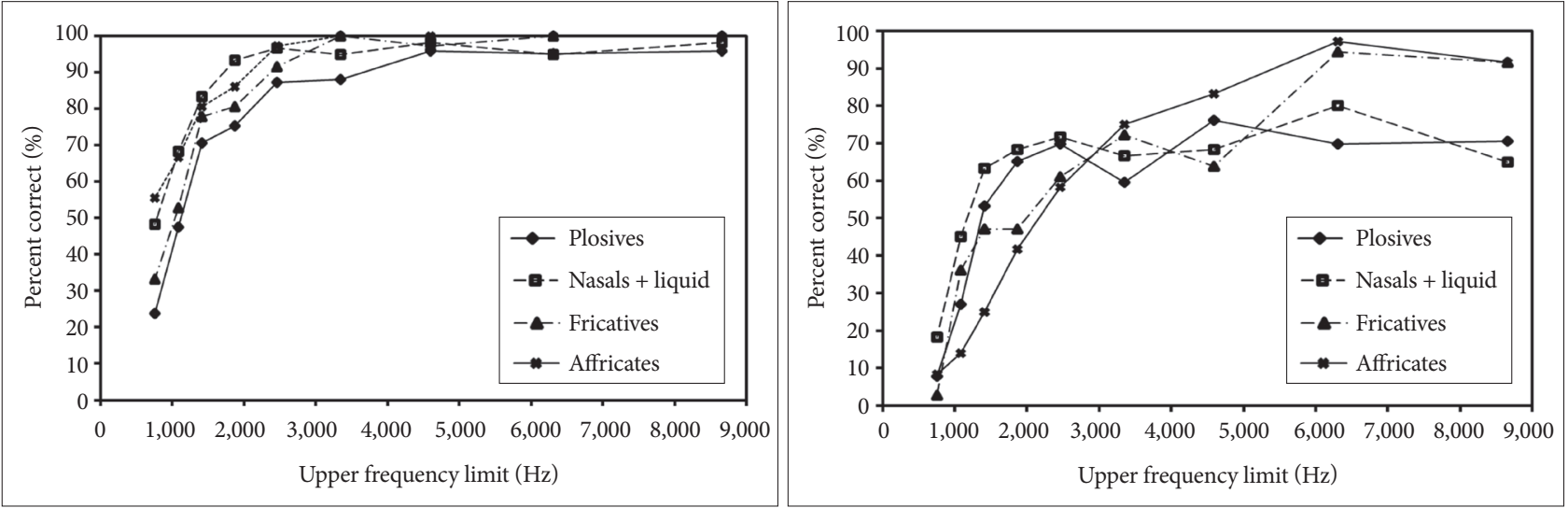

Figure 6. Consonant recognition errors by band-pass frequency cutting and manner of articulation of $\mathrm{NH}(n=3)$ and $\mathrm{Cl}$ subjects $(n=2)$. NH: normal hearing, $\mathrm{Cl}$ : cochlear implant.
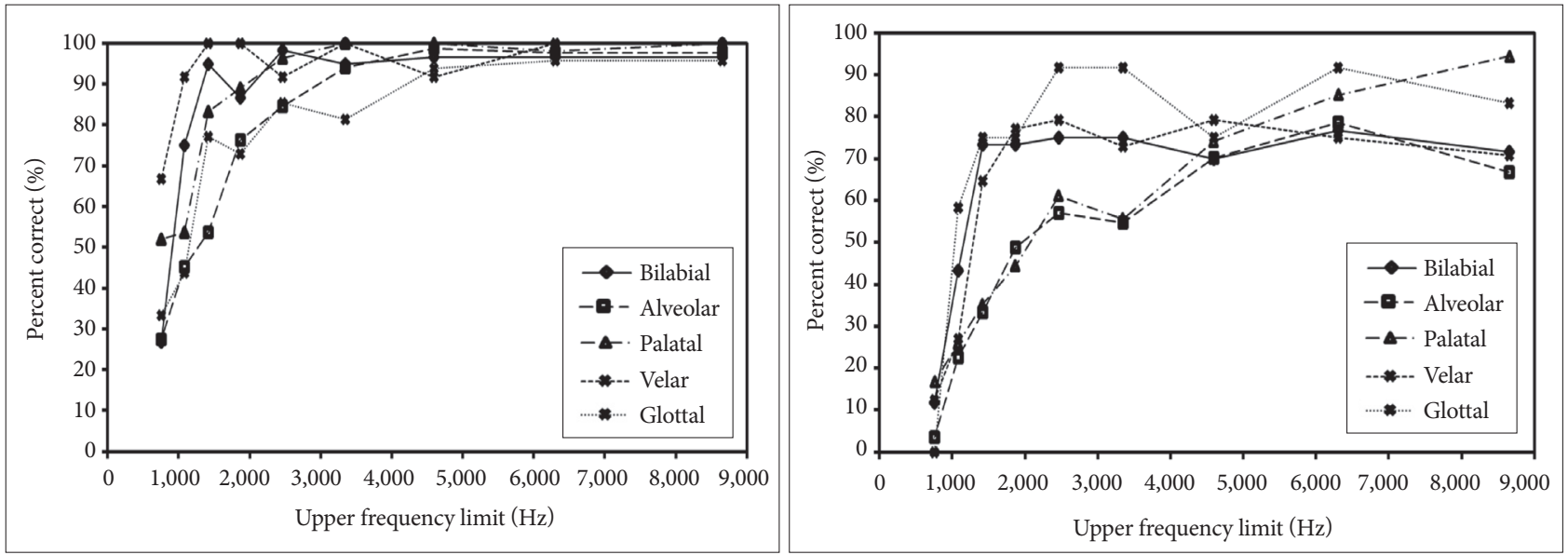

Figure 7. Consonant recognition errors by band-pass frequency cutting and place of articulation of $\mathrm{NH}(n=3)$ and $\mathrm{Cl}$ subjects $(n=2)$. $\mathrm{NH}$ : normal hearing, $\mathrm{Cl}$ : cochlear implant.

tion from $120 \mathrm{~Hz}$ to $8,658 \mathrm{~Hz}$ might be due to the following several reasons: first, mono-aural input in the test setting could be one of them. Mono-aural speech input could be difficult condition for consonant recognition and even more difficult for the CI subjects. Second, each consonant in each syllable condition and frequency band had only one opportunity to be heard so that mistakes and attention problems were not controlled and reflected in the error scores. Third, the frequency bands were randomized to get more objectivity against the learning effects, but it brought frustration when the much reduction was presented at the earlier period of test session and made the subjects give up to listen more carefully afterward. This phenomenon was predominant in CI \#3. This kind of test procedure could be modified as in Milchard \& Cullington (2004) to start with the easiest condition and prevent them becoming frustrated from finding the test too difficult. In this study, a random order of word presentations was employed so that would be enough to minimize learning effects.
The VCV condition was the easiest to recognize consonants as expected and the CV condition was more difficult than VC. It is duplicating Lee \& Lee (2000), but contradictory to Noh \& Lee (2012). According to these results, information that the adjacent vowels might be helpful for consonant recognition, besides it seems that in Korean preceding vowels had better information for recognition than following vowels had. Also, easy recognition of post-vocalic consonants is one of specific features for Korean language (Lee \& Lee, 2000). Besides, Korean consonants cannot stand alone without vowels and the VCV condition is more frequent in Korean than English so that Korean could have advantage in consonant recognition over English.

In both groups, $/ \mathrm{t}^{\mathrm{h}} /$ was the most difficult consonant in Korean. In English, there are consonants like /f, v, $\theta$, $/$ / which place in higher frequency range and have less energy than $/ \mathrm{t}^{\mathrm{h}} /$ in Korean (Valimaa et al., 2002). $/ \mathrm{s} /$ and $/ \mathrm{t}^{\mathrm{h}} /$ are the highest ones among higher frequency consonants in Korean and the subjects in this study definitely showed the greatest difficulty in the high fre- 
quency consonant recognition whereas less errors in $/ \mathrm{s} /$ than $/ \mathrm{t}^{\mathrm{h}} /$, which can be explained that $/ \mathrm{s} /$ phoneme has longer duration of sound than that of $/ \mathrm{t}^{\mathrm{h}} /$ phoneme. Easy-to-recognize consonants were diverse in both groups. $\mathrm{NH}$ and $\mathrm{CI}$ group recognized the lax affricate sound /tc/ easiest in the VCV condition. And NH group showed the least errors in nasal sounds in CV $(/ \mathrm{m} /)$ and VC $(/ \mathrm{n}\urcorner /)$ whereas CI group made the least errors in plosive sounds in $\mathrm{CV}$ $\left(/ \mathrm{k}^{\mathrm{h}} /\right)$ and $\mathrm{VC}(/ \mathrm{p} \neg /)$ conditions. Interestingly, in the CV condition, /la/ was the difficult consonant in CI group, which was one of the easy consonants in the $\mathrm{NH}$ group. In the overall perspective, the CI group had difficulties in recognition of nasal and liquid sounds which has lower frequency bands and showed the less errors in NH group. It might be explained that plosive sounds have noise burst which is amplified much in CI device so that recognized easily by $\mathrm{CI}$ subjects. Another probable explanation of this result is that the Nucleus CI electrodes are typically not inserted deep enough in the apical turn which is really responsible for recognizing nasal and liquid sounds.

In the $\mathrm{NH}$ group, the initial consonant confusion started with the place of articulation and with consonants in relatively low frequency location such as $/ \mathrm{p} /, / \mathrm{t} /, / \mathrm{t} * /, / \mathrm{d} /, / \mathrm{n} /, / 1 /$, and $/ \mathrm{m} /$. And $/ \mathrm{t}^{\mathrm{h}} /$ error, which was the most frequent one, started with 3,347 or $2,463 \mathrm{~Hz}$ band. With this result, it seems that the error pattern is more in a uniform deficit (Hornsby \& Ricketts, 2006), however in the CI group, the error of high frequency consonants as well as hard-to-discriminate consonants started from the 8,658 $\mathrm{Hz}$ band. Besides, the total error percentages showed that high frequency consonants were harder than low frequency consonants, which might support frequency-specific effect in speech recognition (Ching et al., 1998; Hogan \& Turner, 1998; Turner \& Cummings, 1999). This might be because CI subjects had had less experience of high frequency (Hornsby \& Ricketts, 2006).

On the other hand, the recognition of consonants seemed to be influenced by other factors. One of them is the linguistic factor that helps or interferes with the speech recognition. Total number of errors revealed that there was a tendency of increasing errors in high frequency consonants. But, $/ \mathrm{p}^{\mathrm{h}} /$ and $/ \mathrm{t} 6 /$ were recognized quite easily although they are relatively high frequency consonants in $\mathrm{NH}$ group. /ap $\mathrm{h} /, / \mathrm{p}^{\mathrm{h}} /$ and $/ \mathrm{t} 6 /$ have meaning as easy vocabulary and /atca/ is a frequently used exclamation expression. In contrast, $/ \mathrm{at}^{\mathrm{h}} \mathrm{a} /$ does not have meaning in Korean. Meaning of the words is helpful for discriminating speech sounds.

The place of articulation was more difficult than the manner of articulation which is consistent to previous researches (Milchard \& Cullington, 2004; Pisoni \& Remez, 2005; Turner \& Brus,
2001; Tyler \& Moore, 1992; Valimaa et al., 2002). CI subjects made more errors in the manner of articulation than $\mathrm{NH}$ subjects and this was more prominent in $\mathrm{CV}$ condition than other conditions.

In Figure 4, errors in CI group markedly increased because of subject \#3. The probable reason is that CI \#3 has been used contralateral HA from her young age and not ceased to use it when she got CI surgery and the initial mapping period. She might not rely much on the $\mathrm{CI}$ for speech recognition. And she showed more frustration on the test than other subjects which might influence on the results.

In this study, the amplitude of stimuli was reduced along frequencies. This could be a compounding factor to the results of this study because amplitude effects are quite important to consonant recognition. Hedrick \& Carney (1997) examined that amplitude effects were more influencing than vowel transition information.

In general, information above $3,000 \mathrm{~Hz}$ conveys little information for consonant recognition on this task in the $\mathrm{NH}$ and $\mathrm{CI}$ subjects. However, some CI subjects did utilize information up to $6,000 \mathrm{~Hz}$. Fricatives and affricates in the manner of articulation and alveolar and palatal in the place of articulation are the ones that benefit from high frequency coding. Alveolar plosive sounds were most difficult sounds in both groups and this confirms previous studies of consonant recognition in Korean. High frequency consonant such as $/ \mathrm{t}^{\mathrm{h}} /$ was difficult for both groups but easy consonants were different in $\mathrm{NH}$ and $\mathrm{CI}$ groups.

\section{Acknowledgments}

This research was supported by a Brain Neuroinformatics Program grant of Core Technology Development Project (10023917-2007-4) from Ministry of Industry \& Energy and Project of Brain Science Fundamental Technology Development grant (20110030102) from Ministry of Education, Science, and Technology.

\section{REFERENCES}

Abraham, S. (1989). Using a phonological framework to describe speech errors of orally trained, hearing-impaired school-agers. Journal of Speech and Hearing Disorders, 54(4), 600-609.

Byrne, D., Dillon, H., Tran, K., Arlinger, S., Wilbraham, K., Cox, R., et al. (1994). An international comparison of long-term average speech spectra. The Journal of the Acoustical Society of America, 96(4), 2108-2120.

Ching, T. Y., Dillon, H., \& Byrne, D. (1998). Speech recognition of hearingimpaired listeners: Predictions from audibility and the limited role of high-frequency amplification. The Journal of the Acoustical Society of America, 103(2), 1128-1140.

De Boysson-Bardies, B., Hallé, P., Sagart, L., \& Durand, C. (1989). A crosslinguistic investigation of vowel formants in babbling. Journal of child language, 16(1), 1-17.

French, N. R. \& Steinberg, J. C. (1947). Factors governing the intelligibility of speech sounds. The Journal of the Acoustical Society of America, 19(1), 90-119.

Friesen, L. M., Shannon, R. V., Baskent, D., \& Wang, X. (2001). Speech rec- 
ognition in noise as a function of the number of spectral channels: Comparison of acoustic hearing and cochlear implants. The Journal of the Acoustical Society of America, 110(2), 1150-1163.

Goodglass, H. (1973). Developmental comparison of vowels and consonants in dichotic listening. Journal of Speech and Hearing Research, 16(4), 744-752.

Hedrick, M. S. \& Carney, A. E. (1997). Effect of relative amplitude and formant transitions on perception of place of articulation by adult listeners with cochlear implants. Journal of Speech, Language, and Hearing Research, 40(6), 1445-1457.

Hochmann, J., Benavides-Varela, S., Nespor, M., \& Mehler, J. (2011). Consonants and vowels: Different roles in early language acquisition. Developmental Science, 14(6), 1445-1458.

Hogan, C. A. \& Turner, C. W. (1998). High-frequency audibility: Benefits for hearing-impaired listeners. The Journal of the Acoustical Society of America, 104(1), 432-441.

Hornsby, B. W. \& Ricketts, T. A. (2006). The effects of hearing loss on the contribution of high-and low-frequency speech information to speech understanding. II. Sloping hearing loss. The Journal of the Acoustical Society of America, 119(3), 1752-1763.

Kim, S. J. \& Lee, E. Y. (2001). A comparative study of Korean and French vowel systems. Speech Sciences, 8(1), 53-66.

Kim, Y. W., Choi, D. L., Lee, S. H., \& Lee, Y. J. (2014). Perceptual characteristics of Korean consonants distorted by the frequency band limitation. Phonetics and Speech Sciences, 6(1), 95-101.

Lee, J. Y. \& Lee, S. H. (2000). A study of consonant perception and production by children with profound sensorineural hearing loss. Korean Journal of Communication Disorders, 5, 159-175.

Lee, K. W. \& Kim, J. S. (2012). The study of frequency importance function of the Korean monosyllabic words. Audiology, 8, 24-33.

Milchard, A. J. \& Cullington, H. E. (2004). An investigation into the effect of limiting the frequency bandwidth of speech on speech recognition in adult cochlear implant users. International Journal of Audiology, 43(6), 356-362.

Miller, G. A. \& Nicely, P. E. (1955). An analysis of perceptual confusions among some English consonants. The Journal of the Acoustical Society of America, 27(2), 338-352.

Murray, N. \& Byrne, D. (1986). Performance of hearing-impaired and normal hearing listeners with various high-frequency cut-offs in hearing aids. Australian Journal Audiology, 8, 21-28.
Noh, H. \& Lee, D. H. (2012). Cross-language identification of long-term average speech spectra in Korean and English: Toward a better understanding of the quantitative difference between two languages. Ear and Hearing, 33(3), 441-443.

Owens, E., Benedict, M., \& Schubert, E. D. (1972). Consonant phonemic errors associated with pure-tone configurations and certain kinds of hearing impairment. Journal of Speech, Language, and Hearing Research, 15(2), 308-322.

Park, J. H. \& Lee, J. H. (2001). Effects of high-frequency hearing loss on speech recognition ability. Communication Sciences and Disorders, 6(1), 1-16.

Pisoni, D. B. \& Remez, R. E. (2005). The Handbook of Speech Perception. Malden, MA: Blackwell Pub.

Rankovic, C. M. (1991). An application of the articulation index to hearing aid fitting. Journal of Speech, Language, and Hearing Research, 34(2), 391-402.

Schow, R. L. \& Nerbonne, M. A. (2002). Introduction to Audiologic Rehabilitation. (4th ed.). Boston, MA: Allyn \& Bacon.

Shannon, R. V. (2002). The relative importance of amplitude, temporal, and spectral cues for cochlear implant processor design. American Journal of Audiology, 11(2), 124-127.

Shannon, R. V., Galvin, J. J. 3rd., \& Baskent, D. (2002). Holes in hearing. Journal of the Association for Research in Otolaryngology, 3(2), 185-199.

Turner, C. W. \& Brus, S. L. (2001). Providing low-and mid-frequency speech information to listeners with sensorineural hearing loss. The Journal of the Acoustical Society of America, 109(6), 2999-3006.

Turner, C. W. \& Cummings, K. J. (1999). Speech audibility for listeners with high-frequency hearing loss. American Journal of Audiology, 8(1), 4756.

Tyler, R. S. \& Moore, B. C. (1992). Consonant recognition by some of the better cochlear-implant patients. The Journal of the Acoustical Society of America, 92(6), 3068-3077.

Välimaa, T. T., Määttä, T. K., Löppönen, H. J., \& Sorri, M. J. (2002). Phoneme recognition and confusions with multichannel cochlear implants: Consonants. Journal of Speech, Language, and Hearing Research, 45(5), 10551069.

Vickers, D. A., Moore, B. C., \& Baer, T. (2001). Effects of low-pass filtering on the intelligibility of speech in quiet for people with and without dead regions at high frequencies. The Journal of the Acoustical Society of America, 110(2), 1164-1175. 